\title{
Traductores ficticios, los caminos sinuosos de la literatura
}

\section{Fictitious Translators, the Sinuous Ways of Literature}

\section{Miguel José CUENCA DROUHARD}

Universidad Carolina de Praga

miguel.cuenca@ff.cuni.cz

Recibido agosto-2019. Revisado: octubre-2019. Aceptado: noviembre-2019.

Resumen: La literatura en lengua checa ha tenido que seguir caminos en ocasiones sinuosos para llegar al lector extranjero. La menor difusión internacional de la lengua de sus autores es una de las causas más importantes de esta circunstancia, aunque no la única, como se expone en el artículo aquí presentado. A diferencia de la literatura española, durante parte del siglo XX se tradujo la literatura checa al castellano y a otras lenguas extranjeras, en su país de origen. En el estudio del camino recorrido por las obras checas e hispanas para llegar hasta el lector, analizaremos la cuestión del traductor ficticio, es decir, la presentación de una traducción como trabajo de una persona distinta del traductor real, con el fin de sortear la censura institucional u otros requisitos administrativos en vigor. Seguiremos también la trayectoria de La guerra de las salamandras de Karel Čapek en castellano, que atraviesa las décadas y sigue reeditándose hasta nuestros días.

En esta comunicación entre dos sistemas literarios, participan diversos elementos, como las relaciones entre Estados, carácter y orientaciones de las editoriales, organización sociopolítica y censura resultante, aspectos macroeconómicos, microeconómicos y otras circunstancias.

Miguel José CUENCA DROUHARD Traductores ficticios, los caminos sinuosos de la literatura 
Palabras clave: Traductores ficticios; literatura checa; Čapek; sistema literario; siglo XX.

\begin{abstract}
The ways followed by Czech literature to reach foreign readers have been sinuous in some occasions. One of the most important reasons of this fact, although not the only one, is the lesser international diffusion of Czech language, as it will be set out in this paper. A particularity of Czech literature is that during the 20th century some translations into Spanish were made in its country of origin. We will explore the ways the Czech and Spanish written literature reach the readers, such as through an unknown and perhaps fictitious translator, practice within the studied period consisting of publishing a translation under a translator name different of the real one, with the purpose of avoiding current official censorship or other administrative requirements. We will follow Čapek's War with the Newts in its journey to Spain over the last decades. In this relationship between two literary systems, several elements play a role, such as Geopolitics, publisher's policies, socio political settings - including censorship - macro economical and micro economical aspects and other circumstances.
\end{abstract}

Key words: Fictitious translators; Czech literature; Čapek; literary system; 20th century.

\title{
1. INTRODUCCIÓN
}

Aunque todas las obras literarias y artísticas en general tienen un autor, no siempre ha sido posible determinar su identidad. Queda patente la abundancia de obras anónimas en los catálogos de la literatura mundial. Otra cuestión relacionada con el tema de la autoría es la del plagio, que goza para sí misma de numerosos estudios monográficos. En el caso de las obras traducidas, podría decirse que el traductor ha venido corriendo peor suerte que el autor, ya que, hasta épocas relativamente recientes, este actor del proceso literario carecía de la relevancia que hoy en día por fortuna se le otorga, no solo en el ámbito de los estudios literarios especializados, sino también dentro de la actividad comercial de las casas editoriales, así como de cara al público lector. Por ello, puede afirmarse que el traductor, acaso por su condición ideal de «invisible» (Venuti 1995, 8), ha sufrido aún con mayor intensidad y frecuencia el anonimato y el plagio, sin entrar en cuestiones de índole pecuniaria. Este trato habitual al traductor resulta incluso más chocante si consideramos que este profesional es también autor creador y no solo actor transmisor, extremo ya aceptado en el ámbito de la Traductología desde hace décadas ${ }^{1}$.

1. «La traducción en tanto que obra es una reproducción artística, la traducción en tanto que proceso es una creación original, la traducción en tanto que género artístico es un caso limítrofe, en la linde entre arte reproductor y creación original» (Levý 1963, 79).

Miguel José CUENCA DROUHARD Traductores ficticios, los caminos sinuosos de la literatura
CLINA

vol. 5-2, December 2019, 147-163

elSSN: 2444-1961

Ediciones Universidad de Salamanca - CC BY-NC-ND 
Queremos plantear aquí la cuestión del traductor que figura en la contraportada de un libro determinado en contraposición al traductor que vierte en persona el texto de una obra extranjera y analizar las causas que conducen a esta ficción de contraportada, a esta -podríamos decir- falsificación. Dicho en lenguaje llano, nos preguntaremos en las líneas que siguen por qué no es el que está y no está el que es. Para ello, nos adentraremos en dos prácticas editoriales muy corrientes respecto a la labor traductora (entre otras) en los dos sistemas culturales que nos ocupan: el checo y el español, dentro del periodo comprendido entre la posguerra española y la desaparición del régimen socialista en Checoslovaquia, dos hitos que han marcado el devenir de las naciones respectivas, así como el de Europa y, en cierta medida, del mundo.

\section{DELIMITACIÓN TERMINOLÓGICA}

En todos los artículos académicos, una de las cuestiones que debe resolver su autor es la selección de denominaciones específicas para unos conceptos dados. No nos encontramos aquí ante ninguna excepción, por lo que a modo de introducción delimitaremos la denominación del concepto principal que rige el desarrollo de este trabajo. Se trata de una labor bastante desagradecida: a menudo no percibida por el lector cuando está bien hecha, y en exceso evidente cuando el resultado se adecúa al nivel apropiado. Además, se trata de una cuestión que suscita numerosas controversias aun sin llegar al fondo del trabajo. Uno de los problemas que se suele presentar es seleccionar una denominación entre las dominantes en distintos periodos, espacios geográficos, corrientes de pensamiento, escuelas, etc. Así pues, para designar al traductor que aparece en la contraportada de una obra y que no corresponde a la persona que realmente ha traducido el texto, encontramos los términos traductor imaginario, traductor fantasma, traductor ficticio o traductor inexistente.

Sin embargo, en este caso nos topamos con el problema añadido de la polisemia. Vemos que dichas denominaciones no solo designan la circunstancia que aquí nos ocupa, sino que además pueden referirse a un recurso literario al que se ha recurrido con frecuencia, que consiste en hacer pasar una obra original por traducción de otra². Nos referimos al ya estudiado fenómeno de la pseudotraducción. La pseudotraducción más famosa de la historia de la literatura acaso sea El ingenioso hidalgo Don Quijote de la Mancha, en cuyas páginas se nos presenta el relato como una traducción de «lengua arábiga» traída por Cidi Hamete Benengeli. La intención de introducir este traductor ficticio en la obra es hacer más aceptable el contenido que si se tratara de una obra escrita originalmente en castellano (Toury 1995, 41) y/o transferir a la

2. Respecto a los conceptos de «original» y «patrón» desde un punto de vista traductológico, ver Králová y Jettmarová (2010, 377).

Miguel José CUENCA DROUHARD Traductores ficticios, los caminos sinuosos de la literatura 
pseudotraducción el prestigio de la supuesta cultura de origen (Toury 1995, 42 y Merino y Rabadán 2002, 24).

Salvando las distancias oportunas, el mismo recurso se emplea en el caso de la llamada «literatura popular» o «literatura de evasión» española, denominaciones que designan en su conjunto a determinadas obras (novelas del Oeste, policiacas y novelas rosas) publicadas con profusión y, por lo general, en formato de bolsillo, durante los años 1940-1970; en este caso, el efecto extranjerizante se obtenía sobre todo haciendo figurar en la portada a un autor ficticio de nombre extranjero, con frecuencia de origen anglosajón. En el contexto económico y cultural de la posguerra española, esto constituía un atractivo para el lector.

En este estudio utilizaremos el término traductor ficticio para referirnos al traductor cuyo nombre figura en la contraportada de una obra, pero no es el que ha vertido en persona el texto, y descartaremos los otros términos ya mencionados por ser portadores de matices semánticos poco adecuados para nuestro objetivo.

\section{CONTEXTO}

El final de la Guerra Civil española abre un nuevo periodo en la historia de España, adelantándose varios años a la posguerra europea que se inicia en 1945. Este paralelismo en los sucesos históricos, lejos de ser casual, es el producto de un mismo sistema, acaso de un polisistema, el europeo, en el que la cultura checa y la española han venido desarrollándose a lo largo de los siglos. Aunque las primeras relaciones entre las culturas y, por consiguiente, las literaturas, checa y española datan de la Edad Media, en la segunda mitad del siglo XX, entendida de manera lata, cobran vigor paulatinamente hasta alcanzar las cotas de intercambios de las que disfrutamos y podemos observar hoy en día: participación en estructuras supranacionales comunes, Centro Cervantes, red de Centros Checos o aprendizaje de idiomas, sin hablar de los numerosos viajes turísticos y operaciones comerciales entre los dos países.

Así pues, no podemos entender el devenir de la cultura checa en el siglo XX sin comprender su contexto europeo, que comparte con otras, como la española. De este modo, es posible comparar, a modo de ilustración, las circunstancias de las dos culturas mencionadas con las de aquellas que evolucionan en un contexto o polisistema distinto, por ejemplo, el iberoamericano. Las sociedades inscritas en este último vivieron la segunda mitad del siglo $x x$ desde una perspectiva y con unas vivencias radicalmente distintas de las experimentadas por los pueblos de las naciones europeas. Resulta obvio añadir que este hecho no constituye ninguna novedad respecto al acontecer de siglos precedentes, durante los cuales se pone de manifiesto la idiosincrasia de las culturas del Nuevo Mundo respecto al Viejo Mundo. En definitiva, cada colectivo es lo que ha sido, sin poder desvincularse de sus experiencias, tanto de los

Miguel José CUENCA DROUHARD Traductores ficticios, los caminos sinuosos de la literatura 
logros como de los fracasos, como nos describe Ortega en su ensayo Historia como sistema al hablarnos del ser del hombre por oposición a la naturaleza de las cosas. Entendemos, por consiguiente, que, aunque a primera vista percibamos una gran diferencia entre las manifestaciones más aparentes del sistema checo y del sistema español -como el idioma, forma de Estado, literatura, arquitectura, gastronomía, etc.-, las circunstancias que comparten tienen gran peso. Dichas circunstancias comunes se han visto multiplicadas por la llegada de la sociedad global, en la que habitantes de muy variados puntos de nuestro planeta consumen los mismos productos (ya sean literarios, audiovisuales, u otros) y comparten las mismas modas, consecuencia de la inmediatez de la comunicación, la proliferación del soporte digital, etc.

Al terminar la última Guerra Mundial, los intereses geopolíticos fueron conformando un nuevo orden europeo (y mundial) en el que España y Checoslovaquia quedaron integradas en campos distintos, diferencia que se acentuaría durante las dos décadas siguientes con la formación de los bloques atlantista (1949) y socialista (1955). Mencionemos que los dos países reanudaron en 1970 sus relaciones comerciales y consulares, interrumpidas desde la segunda posguerra europea. Como consecuencia de tal interrupción, los intercambios culturales quedaron restringidos, en comparación con el periodo 1918-1939³, con una tendencia al alza en la publicación de literatura checa (en menor medida, eslovaca) en España a lo largo de los años. Si en la década de los 60 se contabiliza 1 obra checa traducida y publicada en España, en los 70 ya son 12 , en los 80 son 24 . Se registran 44 títulos en los $90^{4}$ y se consagra así en esta última década del siglo XX el gran «salto» de la literatura checa al mercado español. A título comparativo, indiquemos que, en los años transcurridos del siglo XXI, el número de obras checas traducidas directamente al español y publicadas en España asciende a poco más de $100^{5}$.

Es evidente pues que la literatura checa ha encontrado un creciente interés en el mercado español, al igual que el resto de obras traducidas. Recordemos que el volumen de traducciones publicadas es notable en comparación con las obras comercializadas

3. Creación del círculo español (1918), acuerdo comercial (1921), convenio de «nación más favorecida» (1925), convenio relativo al reconocimiento y ejecución de decisiones judiciales (1927), exposición del libro español (1930), acuerdo para la supresión recíproca de visados (1932), etc.

4. Recuento de publicaciones efectuado por el autor según datos de la BNE y de la agencia española del ISBN.

5. Desde 2001 hasta finales de 2018 hemos contabilizado 104, incluyendo reediciones de traducciones existentes y realizadas durante el siglo XX, como el caso de La Guerra de las Salamandras, de Anna Falbrová, aquí expuesto, numerosas obras de Milan Kundera, etc.

Miguel José CUENCA DROUHARD Traductores ficticios, los caminos sinuosos de la literatura
CLINA

vol. 5-2, December 2019, 147-163

elSSN: 2444-1961

Ediciones Universidad de Salamanca - CC BY-NC-ND 
en su idioma original. En concreto, representan el 20,1\% de la producción de libros en España ${ }^{6}$.

En el entorno literario checoslovaco, la segunda mitad del siglo XX, al menos hasta los años 90, estuvo marcada por una serie de restricciones que, al igual que en el caso español, estaban destinadas a controlar la opinión pública y a hacer prevalecer en la sociedad determinadas posiciones ideológicas ${ }^{7}$. Entre dichas restricciones se encontraba la censura de libros. Hubo medidas para materializar dicha censura comunes en ambos países, aunque también existen diferencias significativas, además de la evolución de los sistemas censores conforme a los cambios sociopolíticos que se producían en cada una de dichas sociedades a lo largo del periodo estudiado. En las siguientes páginas se exponen tales procedimientos enmarcados en su correspondiente contexto.

\section{PARTICULARIDADES DE LA ACTIVIDAD EDITORIAL CHECOSLOVACA}

En el caso checoslovaco, la ley de censura existente en 1948, año de instauración del régimen socialista, era la ley de censura de 1867, con el paréntesis de la ocupación alemana (1938-1945). A partir de febrero de 1948, se decretó el cierre o nacionalización de numerosas casas editoriales y de artes gráficas, lo que aumentó el control de las publicaciones, aunque no de manera sistemática.

En 1950 se aprobó la Ley de Prensa. Desde 1951, todas las publicaciones periódicas tenían asignadas uno o varios redactores censores. Cada casa editorial debía tener un plan de publicaciones obligatoriamente aprobado por el Comité Central del Partido Comunista checoslovaco. En 1953 se creó en secreto la Administración Central de Supervisión de la Prensa, órgano que pasó a depender del Ministerio del Interior en 1954. La censura se ejercía de manera previa y posterior a la publicación. En líneas generales, la llegada de la década de los 60 supuso una suavización de la censura, llegando a desaparecer oficialmente durante la primavera y verano de 1968 (ley 84/1968).

El periodo denominado «Normalización» (1968-1989) trajo consigo una depuración ideológica que afectó a todos los estamentos de la sociedad, desde miembros del

6. Datos referentes a 2017 recopilados por el Instituto Nacional de Estadística de España (https://www.ine.es/prensa/epel_2017.pdf).

7. Traducción y censura es una cuestión ampliamente estudiada por el grupo de investigación TRACE, de la Universidad de León (España), en los distintos géneros literarios, especialmente entre el inglés y el español. Desde 2017 existe un nuevo grupo de investigación, TRACTITEL, que se ocupa, entre otros, del tema mencionado (https://trace.unileon.es/es/presentacion/ grupo-de-investigacion).

Miguel José CUENCA DROUHARD Traductores ficticios, los caminos sinuosos de la literatura 
Partido Comunista hasta escritores, traductores, etc. Ello estuvo acompañado por la aparición de un nuevo sistema de censura, no tan estructurado como en la década de los sesenta, sino formado por una trama de permisos y sanciones de gran efectividad, ya que incitaba a la autocensura. Por otra parte, determinados escritores, traductores, etc. tenían prohibido ejercer su profesión. Así pues, se generalizó una argucia para sortear los mecanismos restrictivos, el llamado «encubrimiento». Este consistía en que un autor "permitido» firmaba el trabajo de otro autor "prohibido", de modo que este último pudiera seguir trabajando a pesar de las restricciones. En palabras del traductor e hispanista Josef Forbelský:

La base era la confianza y la fidelidad. Pero nadie quería hablar de ello. En una ocasión me pidieron de [la editorial] Vyšehrad que encubriera la novela Un hombre que se parecía a Orestes, del autor gallego Álvaro Cunqueiro, traducida por Josef Kostohryz, el cual pasó muchos años en las prisiones comunistas. Como en aquel entonces ya estaba yo encubriendo otro libro, no era posible utilizar el nombre Josef Forbelský. Así pues, usé el apellido de mi cuñado, Suda. Era evidente que yo no podía haber traducido dos libros en un plazo tan corto (Rubaš 2012, 89) ${ }^{8}$.

El testimonio de Josef Čermák, traductor y docente universitario, nos describe otros detalles del encubrimiento:

No se hablaba de ello, pero se sabía que existía y se practicaba a gran escala. Yo guardaba anotadas algunas cosas en secreto, para evitar equivocarme. Nuestros redactores [en la editorial Odeon] querían calidad, por eso solo quería colaborar con los mejores de cada especialidad. Y los que estaban prohibidos solían ser al mismo tiempo los mejores. Yo también me convertí en encubridor a partir de 1952, firmando la traducción del profesor Černý «Crónica del reinado de Carlos IX», de Mérimée. Pero durante la normalización, había incluso autores que se negaban a publicar con otro nombre y preferían silenciarse. También tuvimos problemas a veces con el encubrimiento. Por ejemplo, cuando el encubridor y el encubierto quedaban en un bar y se dejaban allí olvidado el cuerpo del delito. Y después venían unos policías a presentárselo al director; al parecer, en el bar había alguien que trabajaba para la policía. Tenía que explicarles que nosotros no éramos una agencia de detectives y que era corriente que algunos se ayudaran entre sí, por ejemplo cuando veían que no iban a poder entregar dentro de plazo (Rubaš 2012, 337).

Antonín Prìdal, uno de los impulsores del trabajo bibliográfico Zam/čovaní překladatelé (1992) [Los traductores silenciados] es uno de los autores encubiertos o silenciados y nos describe este fenómeno, respondiendo a la pregunta "¿Sabía usted qué amplitud tenía el encubrimiento en los años setenta?»:

\section{8. [Traducción de Miguel Cuenca]}

Miguel José CUENCA DROUHARD Traductores ficticios, los caminos sinuosos de la literatura 
No. No podía ni debía saberlo nadie. Se lo ocultaban los mismos redactores unos a otros, mucho menos las editoriales. Algunas veces se me pasó por la cabeza, pero solo al leer en el pie de imprenta el nombre de alguien que no había figurado hasta entonces como traductor (Rubaš 2012, 337).

Otra particularidad del sector editorial checo durante la segunda mitad del siglo XX es la publicación de literatura checa ya traducida a lenguas extranjeras. Entre ellas, al español. Uno de los factores que motivó esta práctica es la difusión internacional minoritaria de la lengua checa. De esta actividad se encargaban unas editoriales determinadas, cuyo plan estaba orientado, cuando menos en parte, al mercado exterior ${ }^{9}$.

Para el sector editorial y la economía checoslovaca en general, la exportación de dichas obras suponía en primer lugar una fuente de divisas, escasas en las primeras décadas tras la II Guerra Mundial, al igual que sucedía en España. Además de obras literarias de autores checos, también se publicaban trabajos de carácter didáctico, como los de la editorial SPN y documentos de carácter propagandístico al servicio de la ideología socialista, como los de la editorial Orbis, aunque esta última publicaba también obras de otra índole.

La estructuración del sector editorial checo seguía el modelo soviético, en el que cada editorial tenía un ámbito de actividad y objetivos definidos. Las editoriales pertenecían al Estado, a organizaciones estatales, a sindicatos o a las regiones.

Si bien es cierto que el contexto sociopolítico de los años cincuenta es bien distinto del de los años ochenta, tanto en Checoslovaquia como en España, en líneas generales el entorno editorial checo estuvo sujeto a la planificación entre los años 1948 y 1990, tanto desde el punto de vista ideológico (censura) como económico (objetivos y restricciones sectoriales, nacionales, etc.).

\section{EDITORIAL ARTIA}

Esta editorial checa estaba especializada en la edición en lenguas extranjeras. Fue fundada en 1953 como sociedad anónima dedicada al comercio exterior (importación y exportación) de bienes culturales. En 1965 pasó a ser por decreto ministerial Sociedad de Comercio Exterior, dependiente del Ministerio de Comercio Exterior. La editorial estaba dividida en cinco secciones comerciales: inglesa, alemana, escandinava, romance y la de países socialistas. También había un departamento dedicado a imprimir libros para editoriales extranjeras, actividad que constituía una notable fuente de ingresos en divisas. La editorial formaba parte del grupo Artia PZO, que desempeñaba

\section{En especial, las casas Artia, Orbis, SPN y Albatros.}

Miguel José CUENCA DROUHARD Traductores ficticios, los caminos sinuosos de la literatura 
diversas actividades de comercio exterior con bienes culturales. La sociedad quedó extinguida en 1990 (Pribáň 2014, 50).

Se trataba de una editorial de carácter especial, ya que estaba destinada a atender la demanda del mercado extranjero. En general, las ediciones solían acordarse previamente con editoriales colaboradoras en el extranjero. Era corriente organizar la traducción y publicación de una obra en distintos idiomas. Cada una de estas versiones aparecía en los países correspondientes figurando el nombre de la editorial colaboradora (Hachette, Doncel, etc.). Sin embargo, en las ediciones para los países del Este figuraba el nombre de Artia. En ocasiones también publicaba a autores checos en el mercado interno.

Entre los autores publicados había tanto clásicos, como contemporáneos: Jan Neruda, Božena Němcová, Jaroslav Hašek, Alois Jirásek, etc.

Gran parte de la actividad de esta casa la constituía la publicación de obras destinadas al público infantil y juvenil. Así pues, se confeccionaron numerosas ediciones en distintos idiomas de cuentos clásicos y modernos, tanto en formato habitual como troquelado, comercializados sobre todo en la década de los 60 . En ocasiones algunos proyectos eran derivados hacia la editorial Albatros, especializada en literatura infantil y juvenil.

\section{EL SISTEMA CENSOR EN ESPAÑA}

En España la censura previa obedecía a una ley de 1883 y un decreto de 1938, hasta la promulgación de la Ley de Prensa de 1966, por la que aquellos quedaban abolidos. Estuvo vigente hasta 1983. Establecía la posibilidad de la denominada consulta voluntaria, que consistía en presentar el texto de la obra antes de su publicación ante las autoridades censoras. Así pues, a partir de 1966, la censura cesó de ser obligatoria, pudiendo no obstante los editores (o autores) someter voluntariamente los textos a la censura, con el fin de evitar procedimientos sancionadores ulteriores, los cuales ya no dependían exclusivamente de los órganos judiciales, sino que podían ser incoados también por autoridades administrativas. Estas últimas quedaban facultadas igualmente para la imposición de sanciones, como cierre de establecimientos, retirada de licencias, multas pecuniarias, etc., todo lo cual no exoneraba de cualquier posible responsabilidad jurídica.

Dentro de este procedimiento de consulta voluntaria, la obra pasaba a ser examinada por un «lector» (censor) que elaboraba un informe en el que indicaba las modificaciones necesarias en el texto antes de ponerse a la venta, o bien recomendaba o desaconsejaba su publicación. Dichos lectores no eran funcionarios de ninguna entidad estatal, sino personas de diversas categorías socioprofesionales que realizaban estas labores por encargo. Se les presuponía una solvencia moral y cierta base cultural

Miguel José CUENCA DROUHARD Traductores ficticios, los caminos sinuosos de la literatura 
que les permitiera analizar las obras literarias. Aunque había unas líneas maestras de censura, cada lector gozaba de amplia discrecionalidad para emitir su dictamen sobre las obras examinadas, como queda patente en los numerosos informes de censura de libros recogidos en los fondos del AGA.

Por otra parte, el sector editorial español, hasta la década de 1980, estaba constituido principalmente por empresas de carácter familiar, con la excepción de algunas editoriales de titularidad pública (como Doncel), que competían entre sí supeditadas a diferentes restricciones según la coyuntura socioeconómica del país, a diferencia del sector editorial checo, que estaba articulado y desempeñaba su actividad conforme a unos presupuestos distintos, como ya se ha indicado.

\section{EL TRADUCTOR DE LA GUERRA DE LAS SALAMANDRAS ${ }^{10}$}

Tales eran las circunstancias en las que se publicó la traducción al español de una obra de Karel Čapek, que, a nuestro entender, es una clara ilustración del proceso que trasladaba la literatura checoslovaca hasta el lector hispanohablante. Nos referimos a la Guerra de las Salamandras, cuyo título original es Válka s mloky. Esta novela de ciencia ficción fue publicada originalmente en 1936, por la casa František Borový, de Praga. La primera traducción de esta obra al castellano que se conozca es la publicada en 1961, en Praga, por la editorial Artia. La traductora fue Anna Falbrová, también citada en ocasiones como Ana Orozco de Falbr. La biografía de esta traductora bien merecería la extensión de un trabajo monográfico. Mencionemos aquí no obstante que era de origen español y que estaba afincada en Checoslovaquia.

Para dilucidar la cuestión del traductor ficticio, era de especial interés conocer las circunstancias en que se publicó la traducción. La información necesaria para tal tarea podría encontrarse en los fondos documentales de la editorial Artia, depositados en el Archivo Estatal checo. Por desgracia, no están organizados de manera que permita su consulta por el público. Así pues, no es posible efectuar un análisis pormenorizado de las circunstancias en que se publicó esta traducción.

Esta traducción vuelve a aparecer en 1965, destinada a Queromón editores, en México, y en La Habana, en 1969. En ambas publicaciones figuraba el nombre de la misma traductora.

Años más tarde, en 1972, la editorial española Doncel, especializada en literatura juvenil y de aventuras, de titularidad estatal, publicó La guerra de las salamandras. En esta edición, figura como traductor José Diéguez. Este nombre no es el de un traductor habitual del checo ni consta que esta persona haya realizado otras traducciones,

10. Esta cuestión ha sido tratada originalmente en nuestra tesis doctoral (2013).

Miguel José CUENCA DROUHARD Traductores ficticios, los caminos sinuosos de la literatura 
por lo que pareció indicado analizar detenidamente la traducción, comenzando por una comparación con la de Falbrová, publicada en Praga en 1961.

\section{ANÁLISIS DE LAS TRADUCCIONES Y SUS CIRCUNSTANCIAS}

Por una parte, observamos que ambas traducciones (Artia 1961 y Doncel 1972) son prácticamente idénticas. Al cotejar ambos textos para detectar dónde se encuentran las contadas diferencias, vemos que la mayoría de ellas consisten en omisiones o sustituciones motivadas por motivos morales (Cuenca 2013, 80).

Una similitud tan manifiesta y unas diferencias tan evidentes y restringidas a determinado tipo nos aconsejaron consultar el Archivo General de la Administración español. En él se hallan depositados los fondos de la editorial Doncel, por haber sido esta de titularidad estatal. Dicha documentación recoge información muy variada: desde nóminas de trabajadores, registros contables y justificantes de pequeños gastos hasta galeradas, informes sobre obras literarias y correspondencia diversa. De este modo, fue posible consultar la documentación relativa a La guerra de las salamandras publicada en 1972.

Entre otros escritos, destacan la carta dirigida por Doncel (en francés) a la agencia literaria checa Dilia, titular de los derechos editoriales correspondientes, en la que solicitaba la autorización para publicar la traducción de Anna Falbrová y la respuesta correspondiente con el permiso y contrato de publicación ${ }^{11}$. Se encuentra también correspondencia interna de la editorial, en la que se menciona en varias ocasiones la necesidad de celebrar un contrato con la traductora e incluso se indica que la obra estaba a punto de ser lanzada al mercado y que aún no se había firmado el contrato. Así pues, durante todo el proceso de edición se conocía en Doncel la autoría de la traducción. Por circunstancias que solo podemos suponer, la novela acabó apareciendo publicada en español con el nombre de José Diéguez como traductor.

Por otra parte, en el AGA encontramos también las galeradas de la publicación presentadas ante el órgano de censura correspondiente. Tras cotejar las galeradas con la novela publicada, salta a la vista que ambos textos son idénticos. No se efectuó ninguna corrección ni eliminación como consecuencia de su paso por la censura. De ello podemos deducir que el texto había sido despojado con anterioridad de todo contenido que pudiera suponer un obstáculo para su publicación.

Todo ello nos conduce a plantearnos determinadas preguntas y a sugerir ciertas hipótesis como respuesta.

11. AGA, cajas 66/19722 y 66/19668.

Miguel José CUENCA DROUHARD Traductores ficticios, los caminos sinuosos de la literatura 
Si la traducción de Artia (1961) y la de Doncel (1972) son idénticas, con la excepción de las omisiones y correcciones motivadas por la censura ¿por qué el nombre del traductor no es el mismo en las dos?

Si las galeradas presentadas a la censura y la novela publicada por Doncel son idénticas, ¿la censura fue efectuada por la editorial? ¿Se trata de una autocensura editorial?

Si José Diéguez era traductor literario de lengua checa ¿cómo es posible que figure como traductor solo en esta obra?

Si José Diéguez trabajó de algún modo para la editorial Doncel ¿cómo es posible que no figure en ninguna nómina ni recibo de pago de honorarios, etc., vista la minuciosidad administrativa observada en la documentación de la editorial? Por otra parte, entre los documentos depositados en el AGA no se encuentra tampoco contrato alguno de traducción o de derechos de traducción con Anna Falbrová.

Por último, en los años 60 y 70 del siglo XX los traductores españoles de checo no eran muy numerosos. José Diéguez debería de haber sido una persona conocida para la comunidad hispanohablante en Praga. Sin embargo, no es así.

Las posibles respuestas a estas preguntas nos indican que, con gran probabilidad, José Diéguez es un traductor ficticio.

Ello puede deberse a motivos políticos. Anna Falbrová, de origen español, se casó con un Richard Falbr, antiguo brigadista en la Guerra Civil, y vivía en Checoslovaquia, país entonces con régimen socialista, lo cual podría haber supuesto un obstáculo político a la hora de superar el control censorio.

Otra hipótesis es que la traductora rechazara los cambios efectuados en su traducción debido a la censura y se negara a firmar el contrato.

Podríamos plantearnos la posibilidad de que Diéguez plagiara a Falbrová. Sin embargo, encontramos en la contraportada de la traducción de aquel la anotación «@ Artia Praha», por lo que la hipótesis del plagio queda descartada. Dicha anotación descarta además la posibilidad de que la editorial recurriera a una traducción realizada en el extranjero para eludir el pago de los derechos correspondientes, práctica corriente en España hasta finales de la década de 1970.

Última hipótesis: por causas administrativas (retraso en la firma del contrato, tramitación de permisos, problemas de comunicación, etc.) no se pudo firmar el contrato con la traductora antes de la publicación, por lo que fue necesario hacer figurar a un traductor ficticio, posiblemente para evitar posibles litigios con los titulares de los derechos de traducción y publicación.

Esta última hipótesis es la más plausible a la luz de la correspondencia encontrada en el AGA. De todas formas, la verificación de este extremo requeriría la consulta de los archivos de Artia. Al ser una editorial estatal dependiente del Ministerio de Comercio Exterior checoslovaco, sus fondos han sido trasladados al Archivo Nacional checo. Por desgracia, dichos fondos no están inventariados y su consulta no es posible, como ya

Miguel José CUENCA DROUHARD Traductores ficticios, los caminos sinuosos de la literatura 
mencionamos anteriormente. Otra fuente importante para el estudio de esta cuestión es la agencia literaria Dilia, titular de los derechos de traducción de la obra que nos ocupa. Esta agencia existe en la actualidad. Lamentablemente, no permite el acceso a su documentación histórica ni consultas al respecto, por lo que no nos ha sido posible verificar el modo en que se despachó el asunto de los derechos de traducción con Anna Falbrová.

En todo caso, es importante mencionar el aspecto económico de la traducción dentro del proceso de edición en general ${ }^{12}$. Se trata de una labor que, como cualquier otra, debe remunerarse, lo cual contribuye a aumentar el coste de publicación. Además, una buena traducción requiere tiempo, factor que repercute así mismo en los costes de producción editorial. A este respecto es ilustrativo mencionar una práctica frecuente durante la posguerra española de algunos editores, los cuales utilizaban traducciones publicadas en el extranjero para lanzar una edición y así no tener que pagar derechos de traducción. Por entonces la casi inexistencia o inaplicación de tratados internacionales sobre derechos de propiedad intelectual y la lenta transmisión de la información posibilitaban este tipo de picaresca (Moret 2002, 64).

La existencia de traductores ficticios, también llamados inexistentes o fantasma, es una cuestión que se ha tratado en varios estudios especializados sobre traducción y prácticas editoriales en España, como las tesis doctorales de Linder Molin (2008:233) ${ }^{13}$, Belotto Martínez (2012:166 y 388) $)^{14}$ y Abio Villarig (2013:155) ${ }^{15}$.

Como se demuestra mediante los casos citados en estos estudios, la reutilización de traducciones existentes, cambiando el nombre del traductor, era práctica corriente, en líneas generales, hasta finales de la década de 1970.

En décadas posteriores, no obstante, se han seguido aprovechando traducciones existentes, esta vez de manera legítima, para lanzar nuevas ediciones de una obra determinada. Aquí encontramos de nuevo el caso de La guerra de las salamandras, cuya traducción de Falbrová ha sido publicada en trece ocasiones desde 1961 hasta nuestros días (si contamos la traducción de José Diéguez), con los oportunos cambios en el texto, como son la recuperación de los pasajes eliminados o modificados por la censura, la actualización del estilo, la corrección de problemas en la traducción o

12. Una práctica muy extendida a lo largo de distintos periodos es la realización de traducciones indirectas, lo cual reduce considerablemente los costes de edición. A este respecto ver Vavroušová (2016:55).

13. Expone el caso de José Antonio Lara, supuesto traductor de The Big Sleep y de The Long Goodbye, de Raymond Chandler, publicadas en castellano por Barral Editores.

14. Cuestiona la existencia de la traductora Mercedes Sala, nombre que figura en repetidas ocasiones en publicaciones de la editorial Edicomunicación.

15. Esta tesis cita de nuevo a José Antonio Lara, así como a Antonio Rubio (Planeta) y a Santiago Ojor (Mépora) como traductores «fantasma».

Miguel José CUENCA DROUHARD Traductores ficticios, los caminos sinuosos de la literatura 
pequeñas erratas, etc. La más reciente data de 2018, publicada por El Zorro Rojo en Barcelona $^{16}$.

La segunda traducción de esta obra que más veces ha sido publicada (3) es la firmada por Carmen Díez de Oñate y Mildred Forrester, realizada a partir del inglés, que salió al mercado de la mano de Revista de Occidente (1945) y de Aguilar, S.A. de Ediciones (1950 y 1964). Su título exacto, que corresponde literalmente al original checo, es Guerra con las Salamandras ${ }^{17}$.

Encontramos también la reutilización de la traducción más antigua de esta obra, la del año 1944. Se trata de la primera versión de Válka s Mloky al español. El título exacto de esta traducción es La Guerra con las Salamandras. Fue realizada por Mauricio Amster, a partir del alemán y publicada en Santiago de Chile por la editorial Zig-Zag. Esta versión se lanzó de nuevo en 2009 en México por parte de la editorial Siglo XXI. En ella consta también el nombre de este traductor.

Por último, entre las traducciones reeditadas, encontramos la más reciente, la realizada por Luz Monteagudo a partir del inglés. Fue publicada por primera vez en la editorial Books4pocket (2009) y por segunda vez en Sirio (2012).

\section{CONCLUSIÓN}

Aunque ninguna de las dos prácticas analizadas pertenece en exclusiva a uno de los sistemas socioculturales mencionados, la prevalencia de cada una de ellas es el resultado de unos valores y circunstancias predominantes en una sociedad dada durante un periodo específico. De este modo, el «encubrimiento» se dio también en España, pero no de una manera tan generalizada, que se podría asimilar a los pseudónimos presentados por autores y traductores españoles normalmente por razones comerciales (Rabadán 2000, 273-274). En cualquier caso, los traductores ficticios, en sus distintas modalidades, constituyen la respuesta de los traductores y de las editoriales a las exigencias que les venían impuestas por la coyuntura de la época en todas sus facetas ${ }^{18}$. En definitiva, a pesar de las dificultades objetivas del periodo estudiado y gracias al empeño y habilidad de numerosos profesionales, la literatura checa y la

16. Ver tabla de traducciones de La Guerra de las Salamandras en el Anexo.

17. Sobre la tradición traductiva en el caso de títulos de obras, entre otros, ver el apartado que Jiří Levý dedica al tema en Umění prekladu (El Arte de Traducir), recogido en Králová y Cuenca (2013:85).

18. Sobre esta cuestión, sería deseable realizar un estudio comparativo sobre el comportamiento de traductores y editoriales ante las restricciones institucionales en distintas sociedades europeas, además de la checa y la española, a lo largo de distintos periodos históricos comunes a las mismas (periodo de entreguerras, postguerra, desarrollo industrial, globalización/ digitalización, etc.).

Miguel José CUENCA DROUHARD Traductores ficticios, los caminos sinuosos de la literatura 
española recorrieron sus caminos sinuosos respectivos hasta arribar a su destino: el lector.

\section{ANEXO}

\begin{tabular}{|c|c|c|c|c|c|}
\hline Año & Título & Traductor & $\begin{array}{l}\text { Lengua } \\
\text { origen }\end{array}$ & Editor & Lugar \\
\hline 1944 & $\begin{array}{l}\text { La guerra con } \\
\text { las salamandras }\end{array}$ & Mauricio Amster & Alemán & Zig-Zag & $\begin{array}{l}\text { Santiago } \\
\text { de Chile }\end{array}$ \\
\hline 1945 & $\begin{array}{l}\text { Guerra con las } \\
\text { salamandras }\end{array}$ & $\begin{array}{l}\text { Carmen Díez de } \\
\text { Oñate y Mildred } \\
\text { Forrester }\end{array}$ & Inglés & Rev. de Occidente & Madrid \\
\hline 1950 & $\begin{array}{l}\text { Guerra con las } \\
\text { salamandras }\end{array}$ & $\begin{array}{l}\text { Carmen Díez de } \\
\text { Oñate y Mildred } \\
\text { Forrester }\end{array}$ & Inglés & $\begin{array}{l}\text { Aguilar, S.A. de } \\
\text { Ediciones }\end{array}$ & Madrid \\
\hline 1961 & $\begin{array}{l}\text { La guerra de las } \\
\text { salamandras }\end{array}$ & Ana Falbrová & Checo & Artia & Praga \\
\hline 1964 & $\begin{array}{l}\text { Guerra con las } \\
\text { salamandras }\end{array}$ & $\begin{array}{l}\text { Carmen Díez de } \\
\text { Oñate y Mildred } \\
\text { Forrester }\end{array}$ & Inglés & $\begin{array}{l}\text { Aguilar, S.A. de } \\
\text { Ediciones }\end{array}$ & Madrid \\
\hline 1965 & $\begin{array}{l}\text { La guerra de las } \\
\text { salamandras }\end{array}$ & Ana Falbrová & Checo & $\begin{array}{l}\text { Artia/Queromón } \\
\text { editores }\end{array}$ & Praga \\
\hline 1969 & $\begin{array}{l}\text { La guerra de las } \\
\text { salamandras }\end{array}$ & Ana Falbrová & Checo & Instituto del Libro & $\begin{array}{l}\text { La } \\
\text { Habana }\end{array}$ \\
\hline 1972 & $\begin{array}{l}\text { La guerra de las } \\
\text { salamandras }\end{array}$ & José Diéguez & Checo & Doncel & Madrid \\
\hline 1978 & $\begin{array}{l}\text { La guerra de las } \\
\text { salamandras }\end{array}$ & Ana Falbrová & Checo & Arte y Literatura & $\begin{array}{l}\text { La } \\
\text { Habana }\end{array}$ \\
\hline 1981 & $\begin{array}{l}\text { La guerra de las } \\
\text { salamandras }\end{array}$ & Ana Falbrová & Checo & Bruguera & Barcelona \\
\hline 1982 & $\begin{array}{l}\text { La guerra de las } \\
\text { salamandras }\end{array}$ & Ana Falbrová & Checo & Bruguera & Barcelona \\
\hline 1992 & $\begin{array}{l}\text { La guerra de las } \\
\text { salamandras }\end{array}$ & $\begin{array}{l}\text { Ana Falbrová / } \\
\text { Ciro Elizondo }\end{array}$ & Checo & Hiperión & Madrid \\
\hline 2003 & $\begin{array}{l}\text { La guerra de las } \\
\text { salamandras }\end{array}$ & Ana Falbrová & Checo & Gigamesh & Barcelona \\
\hline
\end{tabular}

Miguel José CUENCA DROUHARD Traductores ficticios, los caminos sinuosos de la literatura 


\begin{tabular}{|c|c|c|c|c|c|}
\hline Año & Título & Traductor & $\begin{array}{l}\text { Lengua } \\
\text { origen }\end{array}$ & Editor & Lugar \\
\hline 2008 & $\begin{array}{l}\text { La guerra de las } \\
\text { salamandras }\end{array}$ & $\begin{array}{l}\text { Luz } \\
\text { Monteagudo }\end{array}$ & Inglés & Books4pocket & Barcelona \\
\hline 2009 & $\begin{array}{l}\text { La guerra de las } \\
\text { salamandras }\end{array}$ & Anna Falbrová & Checo & Gigamesh & Barcelona \\
\hline 2009 & $\begin{array}{l}\text { La guerra con } \\
\text { las salamandras }\end{array}$ & Mauricio Amster & Alemán & Siglo XXI & México \\
\hline 2010 & $\begin{array}{l}\text { La guerra de las } \\
\text { salamandras }\end{array}$ & Helena Voldan & Checo & $\begin{array}{l}\text { Ekumene Comenius } \\
\text { Cultural Centre }\end{array}$ & $\begin{array}{l}\text { Buenos } \\
\text { Aires }\end{array}$ \\
\hline 2012 & $\begin{array}{l}\text { La guerra de las } \\
\text { salamandras }\end{array}$ & $\begin{array}{l}\text { Luz } \\
\text { Monteagudo }\end{array}$ & Inglés & Sirio & Málaga \\
\hline 2015 & $\begin{array}{l}\text { La guerra de las } \\
\text { salamandras }\end{array}$ & Ana Falbrová & Checo & Weston & Tenerife \\
\hline 2017 & $\begin{array}{l}\text { La guerra de las } \\
\text { salamandras }\end{array}$ & Ana Falbrová & Checo & Gigamesh & Madrid \\
\hline 2018 & $\begin{array}{l}\text { La guerra de las } \\
\text { salamandras }\end{array}$ & Ana Falbrová & Checo & El Zorro Rojo & Barcelona \\
\hline
\end{tabular}

Tabla 1. Publicaciones en español de Válka s mloky

(La guerra de las salamandras) de Karel Čapek.

\section{BIBLIOGRAFÍA}

ABIO VILLARIG, Carlos. 2013. «Políticas de Traducción y Censura en la Novela Negra Norteamericana publicada en España durante la II República y la Dictadura Franquista (1931-1975)». Tesis doctoral. Universidad de Alicante.

BELOTTO MARTínEZ, Jesús. 2012. «La traducción y recepción del poema en prosa en España: Le Spleen de Paris de Charles Baudelaire». Tesis doctoral. Universidad de Alicante.

CUENCA DROUHARD, Miguel José. 2013. «La influencia del polisistema cultural español en la traducción de la literatura checa durante la segunda mitad del siglo XX». Tesis doctoral. Universidad Carolina de Praga.

KRÁLOVÁ, Jana y Miguel José CUENCA DROUHARD (eds.). 2013. Jiri Levý: Una concepción (re) descubierta. Soria: Hermeneus.

KRÁLOVÁ Jana y Zuzana JETTMAROVÁ. 2010. «Historia de la traducción: fuente de inspiración». En Lengua, traducción, recepción. En honor a Julio César Santoyo, ed. por Juan José LANERO y José Luis CHAMOSA. León: Universidad de León.

LEVÝ, Jiří. 1996 (1957). České teorie překladu 1, 2. Praha: Ivo Železný.

Miguel José CUENCA DROUHARD Traductores ficticios, los caminos sinuosos de la literatura 
LINDER MOLIN, Daniel Peter. 2008. «The American Detective Novel in Translation: The Translations of Raymond Chandler's Novels into Spanish». Tesis doctoral. Universidad de Salamanca.

MERINO, Raquel y Rosa RABADÁN. 2002. "Censored Translations in Franco's Spain: The TRACE Project - Theatre and Fiction (English-Spanish)». TTR 15 (2), 125-152. https://doi. org/10.7202/007481ar.

MORET, Xavier. 2002. Tiempo de editores. Historia de la edición en España, 1939-1975. Madrid: Ediciones Destino.

PŘIBÁŇ, Michal et al. 2014. Česká Literární Nakladatelství 1949-1989. Praha: Academia.

RABADÁN, Rosa (ed.). 2000. Traducción y censura inglés-español: 1939-1985. Estudio preliminar. León: Universidad de León.

RUBÁŠ, Stanislav (ed.). 2012. Slovo za slovem. Praha: Academia.

TOURY, Gideon. 1995. Descriptive translation studies and beyond. Ámsterdam: J. Benjamins Publishing Company.

VENUTI, Lawrence. 1995. The Translator's Invisibility: A History of Translation. Londres: Routledge.

\section{Fuentes}

Agencia española del ISBN. Base de datos de libros editados en España. http://www. culturaydeporte.gob.es/cultura-mecd/areas-cultura/libro/bases-de-datos-del-isbn/basede-datos-de-libros.html. Fecha de acceso junio de 2019.

Biblioteca Nacional de España. Catálogo general. http://catalogo.bne.es/uhtbin/webcat. Fecha de acceso junio de 2019.

Biblioteca Nacional de la República Checa. Catálogo general. https://aleph.nkp.cz. Fecha de acceso junio de 2019.

Instituto Nacional de Estadística. Notas de prensa publicadas. https://www.ine.es/prensa/ epel_2017.pdf. Fecha de acceso junio de 2019.

Miguel José CUENCA DROUHARD Traductores ficticios, los caminos sinuosos de la literatura 
